\title{
Lectin typing of methicillin-resistant Staphylococcus aureus from Singapore, England and Wales, and Denmark
}

\author{
J. O. JARLØV*, V.T. ROSDAHL, M. YEO† and R. R. MARPLES $\ddagger$
}

Staphylococcus Laboratory, Division of Preventive Microbiology, Statens Seruminstitut, Copenhagen, Denmark $\dagger$ †epartment of Pathology. Singapore General Hospital, Singapore and $\ddagger$ Staphylococcus Reference Laboratory, Central Public Health Laboratory, London

\begin{abstract}
Summary. Methicillin-resistant Staphylococcus aureus (MRSA) isolates from a possible outbreak in Singapore (84) were examined together with all MRSA isolated in Denmark in 1986-1990 (58) and 14 distinct epidemic and 10 distinct single hospital strains from England and Wales. All 84 Singapore isolates were phage typed routinely and 52 isolates were further analysed together with the Danish isolates with an additional set of experimental phages and by lectin typing. The British strains, previously phage typed in the same way, were lectin typed. The following lectins were used: wheat-term agglutinin, soy-bean agglutinin, tomato lectin and Concanavalin-A. Routine phage typing of the Danish isolates showed that 41 isolates belonged to 19 different types; 17 isolates were non-typable (NT). Addition of experimental phage typing and lectin typing enhanced discrimination to 47 types. The 24 British strains could be divided into nine "lectin types". Sixty-one of the isolates from Singapore were non-typable by phage typing; the remaining 23 strains belonged to five types. Further examination of 52 isolates with the experimental set of phages and by lectin typing gave 14 closely related types; $48 \%$ of these isolates belonged to only two types.
\end{abstract}

\section{Introduction}

Methicillin-resistant strains of Staphylococcus aureus, (MRSA), have caused hospital epidemics throughout the world ${ }^{1-5}$ and the spread of MRSA in hospitals continues to be a major problem in most countries. Phage typing has been a powerful tool for typing $S$. aureus. ${ }^{6}$ However, when phage typing is applied to MRSA, many strains are non-typable (NT) and the rest give only a restricted number of phage reactions with the International set of phages. ${ }^{3,7,8}$ This may reflect the possibility that most MRSA belong to only a few clones that have spread worldwide. The introduction of a set of phages especially for typing MRSA has shown a greater diversity ${ }^{7}$ and other typing methods may enhance discrimination.

Lectins are proteins or glycoproteins characterised by their ability to react specifically with carbohydrates $^{9-13}$ and have been used for several investigations in clinical microbiology..$^{13}$ Recently we described the typing of $S$. epidermidis by means of lectins-wheat-germ agglutinin, soy-bean agglutinin, Lens culinaris agglutinin and Concanavalin-A. ${ }^{14}$ The aim of the present study was to assess the value of

Received 29 Oct. 1992; revised version accepted 20 March 1993. * Present address, to which correspondence should be sent: Department of Clinical Microbiology, Afsnit 7806, Rigshospitalet, 20 Tagensvej, DK2200, Copenhagen N, Denmark. lectin typing by applying it to MRSA isolates from a possible hospital outbreak (Singapore), to MRSA of independent origin isolated in Denmark during 1986-1990 and to the distinct British epidemic and endemic MRSA strains.

\section{Materials and methods}

\section{MRSA strains}

Isolates from Denmark. A total of 58 MRSA isolates from the period 1986-1990 was investigated (table I). These MRSA represent one strain from each of all patients in Denmark with known MRSA colonisation or infection. Wherever possible, clinical information was obtained and the probability of the isolates being imported to Denmark was evaluated.

Isolates from England and Wales. Fourteen different MRSA strains identified as "epidemic" strains, ${ }^{7}$ (i.e., strains found at several hospitals in a region) were examined, together with 10 different strains found in only one hospital per region ("endemic" hospital strains). All of these strains had been characterised previously. ${ }^{2}$

Isolates from Singapore. Eighty-four isolates which represented one isolate per patient from an apparent hospital outbreak in Singapore were examined. The isolates were collected during December 1989 and 
Table I. Phage groups of MRSA isolated in Denmark 1986-1990

\begin{tabular}{|c|c|c|c|c|c|c|c|c|}
\hline \multirow{2}{*}{ Year } & \multicolumn{7}{|c|}{ Number of isolates of phage groups } & \multirow{2}{*}{ Total } \\
\hline & I & II & III & $83 \mathrm{~A}$ & 80 & NI & NT & \\
\hline 1986 & 1 & 0 & $3(2)^{*}$ & $4(3)$ & 0 & 0 & $5(3)$ & $13(8)$ \\
\hline 1987 & 0 & 0 & $8(1)$ & $4(2)$ & 0 & 0 & $2(2)$ & $14(5)$ \\
\hline 1988 & 0 & 0 & $2(2)$ & $6(3)$ & 0 & 0 & $4(2)$ & $12(7)$ \\
\hline 1989 & $1(1)$ & 0 & $4(1)$ & $2(1)$ & 1 & 0 & $2(2)$ & $10(5)$ \\
\hline 1990 & 0 & 0 & $3(2)$ & $1(1)$ & 0 & $1(1)$ & $4(1)$ & $9(5)$ \\
\hline Total & $2(1)$ & 0 & $20(8)$ & $17(10)$ & 1 & $1(1)$ & $17(10)$ & $58(30)$ \\
\hline
\end{tabular}

*( ), Imported strains.

January 1990 and sent to the Staphylococcus Reference Laboratory, Statens Seruminstitut, Copenhagen for phage typing and further evaluation. All isolates were phage typed with the International set of phages; 52 of these isolates were analysed further (table III). These isolates originated from skin (17), airways (either endotracheal aspirate or sputum) (13), skin abscesses or wounds (5), blood cultures (5), intravenous devices (5), orthopaedic devices or bones (4) and nasal cultures (3). Clinical information and evaluation concerning the bacteria causing infection or colonisation were not available.

\section{Phage typing}

The isolates from Denmark and Singapore were phage typed according to Blair and Williams ${ }^{6}$ as described by Rosdahl and Knudsen. ${ }^{8}$ The International set of phages was applied together with nine additional phages especially chosen for methicillin-resistant strains (phages 616, 618, 620, 622, $623,625,626,629$ and 630) suggested by Richardson et al. ${ }^{7}$

\section{Antibiotic susceptibility testing}

The isolates from Denmark and Singapore were tested for resistance to methicillin by means of a tablet diffusion assay on salt $7 \cdot 5 \%$ agar plates incubated at $30^{\circ} \mathrm{C}$ for $48 \mathrm{~h}^{15}$

\section{Lectin typing}

The typing of $S$. epidermidis with lectins has been described previously. ${ }^{14}$ The following biotinylated lectins were applied: wheat-germ agglutinin (WGA), ${ }^{9,12}$ soy-bean lectin (SBA), ${ }^{9,10,12}$ Lysopersicon esculentum agglutinin (LEA: tomato lectin) ${ }^{11}$ and Concanavalin-A (Con-A). ${ }^{9}$ WGA, SBA and Con-A have been used for typing $S$. epidermidis. ${ }^{14} \mathrm{LEA}$ has a carbohydrate specificity for N-linked, tetra-antennary complex type glycans. The lectin-glycan binding is inhibited by polymers of $\mathrm{N}$-acetyl-lactosamine. ${ }^{11}$

Briefly, whole bacteria were bound in microtitration plates and then incubated with biotinylated lectin followed by incubation with peroxidase-conjugated avidin and a peroxidase substrate. The amount of bound lectin was measured with an ELISA reader at $492 \mathrm{~nm}$. All tests were done in triplicate. Controls with and without bacteria and lectins were included in each plate. Reproducibility was determined by investigating the same strains of $S$. aureus in different plates and on different days. Three strains of $S$. epidermidis used in a previous study, ${ }^{14}$ representing different reactions to the lectins, were used as an additional control in all plates to evaluate variations in lectin activity.

Results were expressed as $\mathrm{OD}_{492}$ values $\times 1000$ for each lectin. Values $<100$ were considered to be negative (non-reactive).

\section{Statistical analysis}

The analytical variation (intra-plate and day-to-day variation) of the lectin binding assay was determined by investigation of double determinations of strains of $S$. aureus. The following formula was used:

$$
\mathrm{SD}=\sqrt{\frac{\Sigma \mathrm{d}^{2}}{2 \mathrm{n}}}
$$

where SD is the standard deviation, $\Sigma \mathrm{d}^{2}$ is the sum of squared differences of double determination of the same strain and $\mathrm{n}$ is the number of strains tested. A total of 18 strains was included; 11 were from this study and the rest represented strains of different phage types and antibiotic resistance patterns. The 18 strains covered the range of responses for the individual lectins.

Isolates were considered to be distinct if their lectin values deviated more than the maximal variation with $95 \%$ confidence limits as calculated for the day-to-day variations-variation day-to-day $\times\left(\sqrt{ } 2 \times t_{95 \%}\right)$.

\section{Results}

\section{Lectin typing}

All $S$. aureus isolates were typable; none gave positive test values with SBA, and SBA was, therefore, omitted.

A considerable variation, up to $100 \%$ when 
Table II. Analytical variation for the lectin binding assay determined by double determination of strains*

\begin{tabular}{ccc}
\hline Lectin $\dagger$ & $\begin{array}{c}\text { Intra-plate } \\
\text { variation (\%) }\end{array}$ & $\begin{array}{c}\text { Day-to-day } \\
\text { variation (\%) }\end{array}$ \\
\hline WGA & $7 \cdot 3$ & $21 \cdot 6$ \\
LEA & $13 \cdot 9$ & 22.5 \\
ConA & 16.6 & $32 \cdot 9$ \\
\hline
\end{tabular}

*A total of 18 S. aureus strains was included in the calculations. †SBA was omitted as no strain reacted with this lectin.

measured as $\mathrm{OD}_{492}$ values, was found between different batches of LEA and, to a lesser extent, for Con-A. As all the control strains were affected in the same way (i.e., either low or high values), the batch-tobatch variability was seemingly not a matter of difference in lectin specificity but rather a matter of difference in activity. The same batch of these lectins was used throughout the investigation.
The intra-plate and day-to-day variation are presented in table II. On the basis of the day-to-day variation it was calculated that differences of values greater than a factor of 1.64, 1.69 and 1.98 for WGA, LEA and ConA, respectively, indicated differences between strains.

\section{Typing of strains}

Danish MRSA isolates 1986-1990. The Staphylococcus Laboratory, Copenhagen, receives all MRSA isolated in Danish microbiology laboratories. During the period 1986-1990 a total of 58 isolates was verified as MRSA; 30 were judged to be imported and 28 nonimported (table I). By routine phage typing, 41 of these strains could be subdivided into 19 different types; 17 isolates were non-typable (table I). Of the 19 different types, 10 were represented by only one isolate each; 31 isolates belonged to nine different types (table III). These 31 isolates and the 17 NT isolates were further

Table III. Typing of MRSA isolated in Denmark 1986-1990.

\begin{tabular}{|c|c|c|c|c|c|c|}
\hline \multirow{2}{*}{$\begin{array}{l}\text { Type } \\
\text { (routine } \\
\text { phage } \\
\text { typing) }\end{array}$} & \multirow{2}{*}{$\begin{array}{l}\text { Number of } \\
\text { isolates }\end{array}$} & \multicolumn{3}{|c|}{ Number of types } & \multicolumn{2}{|c|}{ "Lectin types" } \\
\hline & & $\begin{array}{l}\text { Experimental } \\
\text { phage } \\
\text { typing }\end{array}$ & $\begin{array}{l}\text { Lectin } \\
\text { typing }\end{array}$ & Both & $\begin{array}{l}\text { WGA/LEA/ConA } \\
\left(\mathrm{OD}_{492} \text { value } \times 1000\right)\end{array}$ & $\begin{array}{l}\text { Number } \\
\text { of } \\
\text { isolates }\end{array}$ \\
\hline NT & 17 & 4 & 8 & 13 & $\begin{array}{l}135 / 876 / 220 \\
379 / 322 / 204 \\
881 / 604 / 103 \\
1048 / 2042 / 302 \\
2564 / 747 / 271 \\
1608 / 2531 / 53 \\
1963 / 2207 / 161 \\
2172 / 2339 / 695\end{array}$ & $\begin{array}{l}1(1)^{*} \\
1(1) \\
1(1) \\
3(2) \dagger \\
2(1) \\
1(1) \\
7(4) \\
1(0)\end{array}$ \\
\hline $77+1-$ & 8 & 5 & 5 & 6 & $\begin{array}{l}546 / 257 / 238 \\
541 / 710 / 107 \\
1319 / 693 / 245 \\
1582 / 1284 / 183 \\
1089 / 2588 / 84\end{array}$ & $\begin{array}{l}2(2) \\
1(0) \\
3(2) \\
1(1) \\
1(0)\end{array}$ \\
\hline 89 & 4 & 2 & 3 & 3 & $\begin{array}{l}520 / 1996 / 160 \\
937 / 2426 / 289 \\
1837 / 1412 / 345\end{array}$ & $\begin{array}{l}1(1) \\
1(0) \\
2(1)\end{array}$ \\
\hline 84 & 4 & 1 & 3 & 3 & $\begin{array}{l}638 / 1713 / 500 \\
1170 / 484 / 327 \\
1666 / 1023 / 392\end{array}$ & $\begin{array}{l}1(1) \\
1(0) \\
2(1)\end{array}$ \\
\hline $84 / 89 / 93$ & 4 & 1 & 3 & 3 & $\begin{array}{l}1284 / 289 / 343 \\
750 / 1423 / 311 \\
1249 / 2481 / 392\end{array}$ & $\begin{array}{l}2(1) \\
1(0) \\
1(1)\end{array}$ \\
\hline $6 / 83 \mathrm{~A} / 75 \mathrm{U}$ & $3+$ & 1 & 1 & 1 & $2323 / 1765 / 300$ & $3(0)$ \\
\hline 93 & 2 & 2 & 1 & 2 & $1923 / 2009 / 327$ & $2(2)$ \\
\hline 85 & 2 & 2 & 2 & 2 & $\begin{array}{l}273 / 340 / 478 \\
1135 / 1978 / 53\end{array}$ & $\begin{array}{l}1(0) \\
1(1)\end{array}$ \\
\hline $83 \mathrm{~A} / 93 / 89$ & 2 & 2 & 2 & 2 & $\begin{array}{l}309 / 1429 / 144 \\
801 / 2650 / 234\end{array}$ & $\begin{array}{l}1(1) \\
1(0)\end{array}$ \\
\hline $77 / 84+/-53$ & 2 & 2 & 2 & 2 & $\begin{array}{l}1468 / 1908 / 379 \\
591 / 178 / 388\end{array}$ & $\begin{array}{l}1(0) \\
1(0)\end{array}$ \\
\hline Total§ & $48(46)$ & 22 & 30 & 37 & & \\
\hline
\end{tabular}

*( ), Imported strains.

+When a "lectin type" contains more than one strain, the $\mathrm{OD}_{492}$ values are the means of the results obtained with all the strains.

$\ddagger$ Three isolates that were epidemiologically related.

$\S$ An additional 10 isolates had different phage types by routine phage typing and were, therefore, not further subtyped. 
Table IV. Typing of MRSA isolates from a possible outbreak in a hospital in Singapore

\begin{tabular}{|c|c|c|c|c|c|c|c|}
\hline \multirow{2}{*}{$\begin{array}{l}\text { Type } \\
\text { (routine } \\
\text { phage } \\
\text { typing) }\end{array}$} & \multicolumn{2}{|c|}{$\begin{array}{l}\text { Number of } \\
\text { isolates }\end{array}$} & \multicolumn{3}{|c|}{$\begin{array}{l}\text { Number of types } \\
\text { identified by }\end{array}$} & \multicolumn{2}{|c|}{ "Lectin types" } \\
\hline & $\begin{array}{l}\text { routine } \\
\text { typing only } \\
(\mathrm{N}=84)\end{array}$ & $\begin{array}{c}\text { supplementary } \\
\text { typing } \\
(\mathrm{N}=52)\end{array}$ & $\begin{array}{l}\text { experimental } \\
\text { phages }\end{array}$ & $\begin{array}{l}\text { lectin } \\
\text { typing }\end{array}$ & both & $\begin{array}{l}\text { WGA/LEA/COnA } \\
\left(\mathrm{OD}_{492} \times 1000\right)\end{array}$ & $\begin{array}{l}\text { Number } \\
\text { of } \\
\text { isolates }\end{array}$ \\
\hline NT & 61 & 36 & 4 & 4 & 8 & $\begin{array}{l}2338 / 2004 / 260^{*} \\
2323 />3000 / 441 \\
1039 / 1057 / 236 \\
2243 / 2056 / 79\end{array}$ & $\begin{array}{r}28 \\
1 \\
4 \\
3\end{array}$ \\
\hline 77 & 6 & 4 & 1 & 2 & 2 & $\begin{array}{l}2335 / 2149 / 421^{*} \\
2505 / 1574 / 133\end{array}$ & $\begin{array}{l}3 \\
1\end{array}$ \\
\hline $77 / 84 / 89$ & 4 & 3 & 1 & 1 & 1 & $2406 / 1726 / 150$ & 3 \\
\hline 85 & 3 & 3 & 1 & 1 & 1 & $2409 / 2182 / 272^{*}$ & 3 \\
\hline $84 / 89$ & 7 & 5 & 1 & 1 & 1 & $2377 / 1754 / 211^{*}$ & 5 \\
\hline $84 / 93$ & 3 & 1 & 1 & 1 & 1 & $2417 / 1669 / 246^{*}$ & 1 \\
\hline Total & 84 & 52 & 10 & 10 & $14 \dagger$ & & \\
\hline
\end{tabular}

*Indistinguishable "lectin types".

†To types comprised $48 \%$ (25 isolates): phage type NT, $622(+)$, "lectin-type" 2440/2098/319 (13 isolates); phage type NT, 618, 622 +, "lectin-type" $2217 / 1954 / 220$ (12 isolates); only the phage types were different.

Table V. Lectin typing of MRSA type-strains from England and Wales

\begin{tabular}{|c|c|c|}
\hline \multirow{2}{*}{$\begin{array}{l}\text { "Lectin type"* } \\
\text { WGA/LEA/ConA } \\
\left(\mathrm{OD}_{492} \times 1000\right)^{*}\end{array}$} & \multirow[b]{2}{*}{ Epidemic strains } & \multirow[b]{2}{*}{ Endemic strains } \\
\hline & & \\
\hline $1988 / 2392 / 434$ & E1, E6 & $\mathrm{H} 4, \mathrm{H} 10$ \\
\hline $1797 / 2942 / 171$ & - & $\mathrm{H} 2, \mathrm{H} 3, \mathrm{H} 5, \mathrm{H} 9$ \\
\hline $1662 / 1253 / 421$ & E12, E13 & - \\
\hline $446 / 1876 / 285 \dagger$ & E3, E4, E5, E7, E8, E11 & H6 \\
\hline $547 / 1760 / 138 \dagger$ & E9 & $\mathrm{H} 7, \mathrm{H} 8$ \\
\hline $133 / 2015 / 465$ & E14 & - \\
\hline $1163 / 1179 / 187$ & $\mathrm{E} 2$ & $\mathrm{H} 1$ \\
\hline $769 / 513 / 488$ & E10 & - \\
\hline
\end{tabular}

*If more than one strain is represented in a "lectin-type", mean values for the included strains are included.

$\dagger \mathrm{E} 9, \mathrm{H} 6$ and $\mathrm{H} 7$ could be placed in either of the marked groups of strains, there was some overlap.

analysed with experimental phages and by lectin typing. Table III also shows the number of different types into which the isolates of each routine phage type could be subdivided. Experimental phages subdivided the 48 isolates into 22 types, whereas lectin typing yielded 30 types and a combination of the two methods produced 37 types. Clinical or bacteriological information on the patients from whom MRSA were isolated, or both, indicated only two examples of apparently related isolates. ${ }^{8}$ The first example included three NT isolates that were not distinguishable by experimental phages and other bacteriological methods, but for which the clinical data did not indicate a connection. Lectin typing placed these three isolates in three different types, and thus supported the clinical conclusion that the isolates were unrelated. The second example comprised three isolates of phage type $6 / 83 \mathrm{~A} / 75 \mathrm{u}$, which by all bacteriological methods (including lectin-typing) were regarded as indistinguishable: the patients from whom they were isolated had been hospitalised on the same ward during the same period. The Danish isolates can thus be regarded as 56 epidemiologically independent cases, which by routine phage-typing could be subdivided into 19 types and 17 NT isolates and where experimental phages added a further subdivision into 32 types, lectin typing into 40 types' and by a combination of both experimental phages and lectin typing, into 47 types. Only one example of transmission could be supported.

MRSA from Singapore. A total of 84 MRSA isolates from a possible outbreak in a Singapore hospital was analysed by routine phage typing (table IV): 61 isolates were NT, 10 belonged to group III and 13 belonged to the closely related $83 \mathrm{~A}$ complex. The subdivision by phage types is shown in table IV; only five different types and NT isolates were found. Further investigation of 52 of these strains with experimental phages and lectin-typing was performed and the resulting subdivision into types by the two methods is also shown in table IV. Only 14 different but closely related types were detected when all methods were included and about half of the strains belonged to two types, separated by only the experimental phages (table IV). Furthermore, 40 of the 52 isolates had indistinguishable "lectin-types". The conclusion was that an epidemiological outbreak had been confirmed.

MRSA from England and Wales. To illustrate the discriminatory power of the lectin binding assay, 14 epidemic and 10 single hospital strains from England and Wales, which previously were found to be different by phage typing and other bacteriological methods, ${ }^{2}$ were lectin typed. As shown in table V, these strains gave a total of nine different types by lectin typing. Six epidemic strains, E3, E4, E5, E7, E8 and E11 were identical by lectin typing and had identical "lectintype" with only one of the single hospital strains (H6), but another epidemic strain, E9, and two single hospital strains, $\mathrm{H} 7$ and $\mathrm{H} 8$ were closely similar (table 
V); some overlap exists between the isolates included in these two "lectin types".

\section{Discussion}

Infection with multiresistant $S$. aureus, including MRSA, is a worldwide problem. In Denmark, such infections are rare ${ }^{8}$-during a 5-year period only 58 isolates of MRSA were found and 30 of these were imported. Epidemiological relatedness was confirmed in only one case in which three patients in the same ward were infected. ${ }^{8}$ Control measures seem to have been effective and this fact, combined with a relatively low usage of cephalosporins in Denmark, is suggested as an important factor. ${ }^{8}$ Control measures should include rapid identification and an effective typing system for MRSA. Phage typing of MRSA with the International set of phages is inadequate..$^{2-4,7,8}$ Therefore, supplementary typing methods are needed and a set of phages especially designed for the typing of MRSA, which enhances discrimination, has been established. ${ }^{7}$ We investigated three different sources of MRSA isolates: 58 from Denmark, of which only three were epidemiologically related; 52 from Singapore which were all epidemiologically related; and 24 British type-strains.

Phage typing combined with lectin typing seems to be a powerful combination for discrimination between MRSA isolates of different origin when the Danish isolates are considered (table III), but for the 24 different British MRSA isolates (table V), lectin typing alone is insufficient as these 24 strains could be divided

\section{References}

1. Chambers HF. Methicillin-resistant staphylococci. Clin Microbiol Rev 1988; 1 : 173-186.

2. Kerr S, Kerr GE, Mackintosh CA, Marples RR. A survey of methicillin-resistant Staphylococcus aureus affecting patients in England and Wales. $J$ Hosp Infect 1990; 16: $35-48$.

3. Khalifa KI, Heiba AA, Hancock G. Nontypeable bacteriophage patterns of methicillin-resistant Staphylococcus aureus involved in a hospital outbreak. $J$ Clin Microbiol 1989; 27: 2249-2251

4. Marples RR, Cooke EM. Current problems with methicillinresistant Staphylococcus aureus. J Hosp Infect 1988; 11: 381-392.

5. Richardson JF, Marples RR. Another strain of methicillinresistant Staphylococcus aureus epidemic in London. Lancet $1988 ; 2$ : 748-749.

6. Blair JE, Williams REO. Phage typing of staphylococci. Bull WHO 1961; 24: 771-784.

7. Richardson JF, Chittasobhon N, Marples RR. Supplementary phages set for the investigation of strains of methicillinresistant Staphylococcus aureus. J Med Microbiol 1988; 25 : 67-74.

8. Rosdah! VT, Knudsen AM. The decline of methicillin resistance among Danish Staphylococcus aureus strains. Infect Control Hosp Epidemiol 1991; 12: 83-88. into only nine "lectin types". Subdivision of the MRSA isolates from a probable outbreak in Singapore resulted in 14 closely related types of which two types accounted for about half of the analysed isolates, indicating the presence of an epidemic of these isolates (table IV).

Variation was found between different batches of the lectins LEA and Con-A. Standardisation of lectin activity is a problem (J.-E. S. Hansen, personal communication); furthermore, some variability in biotinylation is possible. The same batch of lectins should be used throughout an investigation. The affinities of WGA, SBA and Con-A have been examined extensively. ${ }^{9,10,12}$ The affinity of LEA is still under investigation, but the specificity seems to be three or more lactosamine units (Gal $\beta 1-4 \mathrm{GlcNAc})$ as found in $\mathrm{N}$-linked tetra-antennary complex type glycans. ${ }^{11}$ Further analysis of LEA is needed to demonstrate the $S$. aureus cell-wall components that interact with this lectin.

Lectin typing seems to offer a valuable supplement to phage typing for the typing of MRSA, as it can be performed rapidly, the reproducibility is acceptable and the discriminatory power is sufficient to allow further subtyping after phage typing. Other lectins may enhance discrimination. The method is inexpensive and is performed with standard ELISA equipment, making the method available to most laboratories.

We thank Mrs Jette Mondrup for skilful technical assistance, and Dr J.-E. S. Hansen for his advice regarding lectins.

9. Debray H, Pierce-Crétel A, Spik G, Montreuil J. Affinity of ten insolubilized lectins towards various glycopeptides with the $\mathrm{N}$-glycosamine linkage and related oligosaccharides. In: Bøg-Hansen TC (ed) Lectins, vol 3. New York, Walter de Gruyter Co. 1983: 335-351.

10. Goldstein IJ, Hayes CE. The lectins: carbohydrate-binding proteins of plants and animals. Adv Carbohydr Chem Biochem 1978; 35: 127-340.

11. Merkle RK, Cummings RD. Relationship of the terminal sequences to the length of poly- $\mathrm{N}$-acetyllactosamine chains in aspargine-linked oligosaccharides from the mouse lymphoma cell line BW5147. Immobilized tomato lectin interacts with high affinity with glycopeptides containing long poly-N-acetyllactosamine chains. J Biol Chem 1987 ; 262: 8179-8189.

12. Osawa $T$, Tsuji $T$. Fractionation and structural assessment of oligosaccharides and glycoproteins by use of immobilized lectins. Ann Rev Biochem 1987; 56: 21-42.

13. Slifkin $M$, Doyle RJ. Lectins and their application in clinical microbiology. Clin Microbiol Rev 1990; 3: 197-218.

14. Jarløv JO, Hansen J-ES, Rosdahl VT, Espersen F. The typing of Staphylococcus epidermidis by a lectin-binding assay. J Med Microbiol 1992; 37: 195-200.

15. Casals JB, Pedersen OG. Tablet sensitivity testing: a comparison of different methods. Acta Pathol Microbiol Scand Sect B $1972 ; 80 ; 806-816$. 